\title{
Comparative Analyses of the Influence of TEOS Additives on the Sintering Kinetics of Nd: YAG Transparent Ceramics
}

\section{Wentao Jia}

Changchun University of Science and Technology

\section{Qinlei Wei}

Changchun Normal University

\section{Hongbo Zhang ( $\sim$ zhb5388460@126.com )}

Changchun University of Science and Technology https://orcid.org/0000-0002-1749-8349

\section{Chunhui Su}

Changchun University of Science and Technology

\section{Guozhong Ren}

Changchun Normal University

\section{Mengjie Zhao}

Changchun Normal University

Chaoyu Ma

Changchun Normal University

\section{Research Article}

Keywords: Nd, YAG transparent ceramics,vacuum sintering,Johnson sintering model,sintering kinetics

Posted Date: March 17th, 2021

DOl: https://doi.org/10.21203/rs.3.rs-303180/v1

License: (c) (i) This work is licensed under a Creative Commons Attribution 4.0 International License. Read Full License 


\title{
Comparative analyses of the influence of TEOS additives on the sintering kinetics of Nd: YAG transparent ceramics
}

\author{
Wentao Jia ${ }^{1}$, Qinlei Wei ${ }^{2}$, Hongbo Zhang ${ }^{1, *}$, \\ Chunhui $\mathrm{Su}^{1,2, *}$, Guozhong Ren ${ }^{2}$, Mengjie Zhao ${ }^{2}$,Chaoyu $\mathrm{Ma}^{2}$ \\ 1. School of Material Science and Engineering, Changchun University of Science and \\ Technology, Changchun 130022, China \\ 2. Changchun Normal University, Changchun 130032, China \\ *zhb5388460@126.com, sch@cust.edu.cn
}

\begin{abstract}
:
In this work, the sintering kinetics of Nd: YAG transparent ceramics under the vacuum environment was studied by the high-temperature solid phase method. The effects of different sintering temperatures and TEOS content on the densification process of Nd: YAG ceramics were studied. Meanwhile, the crystal structure of Nd: YAG transparent ceramics doped with different contents of TEOS was studied by X-ray diffractometer (XRD) and differential thermal analysis (DTA). The micrographs of ceramics samples were analyzed by scanning electron microscope (SEM). The green sample is heated to $1450 \sim 1650^{\circ} \mathrm{C}$ for $0 \sim 2 \mathrm{~h}$ at a heating rate of $20^{\circ} \mathrm{C} / \mathrm{min}$ in a vacuum environment $\left(\mathrm{P}_{\mathrm{T}} \leq 10^{-6} \mathrm{~Pa}\right)$, and the shrinkage of ceramic samples was analyzed in the vacuum atmosphere by the Johnson sintering model. The sintering activation energy of Nd: YAG transparent ceramics doped with different contents of TEOS was obtained. The results indicated that the addition of TEOS promoted the densification of ceramic samples. The grain size and relative density of ceramic samples increased, and the sintering activation energy decreased with the increase of TEOS content.
\end{abstract}

Keyword: Nd: YAG transparent ceramics; vacuum sintering; Johnson sintering model; sintering kinetics.

\section{Introduction}

Nd: YAG transparent ceramics are widely used in the field of laser materials due to their excellent optical performance. Compared to the Nd: YAG single crystal, Nd: YAG transparent ceramics has the advantages of shorter production cycles, higher ion doping concentration, and no size and shape restriction. Therefore, YAG transparent ceramics is the best substitute for YAG single crystal in the field of laser materials [1-5]. Nd: YAG transparent ceramics are polycrystalline materials, whose microstructure includes grains, grain boundaries, the second phase, pores, and so on. Due to the existence of macroscopic defects, the light transmittance of the ceramic material is reduced $[6,7]$. Compared with the co-precipitation synthesis process of YAG powder, solid state reaction (SSR) sintering is relatively simple [8]. $\mathrm{Nd}_{2} \mathrm{O}_{3}$, $\mathrm{Al}_{2} \mathrm{O}_{3}$, and $\mathrm{Y}_{2} \mathrm{O}_{3}$ powders are mixed in a stoichiometric ratio, and a phase formation process occurred during the sintering process. Therefore, the preparation of high-quality Nd: YAG transparent ceramics through solid-state reaction has been widely recognized by the scientific community.

At present, the sintering mechanism of Nd: YAG transparent ceramics was reported less, 
especially in the experiment. Scientists generally agree that the main driving force of the sintering of transparent ceramics is the decrease in surface energy due to a reduction in the surface area $[9,10]$. The common diffusion types of transparent ceramics are surface diffusion, volume diffusion, and grain boundary diffusion. the sintering process of transparent ceramics is not only affected by the sintering atmosphere, but also by the sintering temperature and sintering aids. Different sintering conditions may be involved different mechanisms during the sintering of Nd: YAG transparent ceramics. Huang et al. studied the apparent activation energy of YAG sintered under the $\mathrm{ArH}_{5}$ atmosphere for densification under the holding and sintering conditions to be $855 \mathrm{~kJ} / \mathrm{mol}$, and the apparent activation energy for grain growth to be $1053 \mathrm{~kJ} / \mathrm{mol}$ [11]. Although researchers have studied the sintering activation energy of $\mathrm{Nd}$ : YAG transparent ceramics, there are few studies on the sintering activation energy obtained under vacuum conditions. The measured sintering curve of transparent ceramics in an air environment cannot accurately reflect the sintering process under vacuum conditions. Meanwhile, the kinetics of liquid phase sintering depends on the quality and quantity of the liquid phase, which is closely related to the wetting characteristics of the liquid-solid phase and the dissolution-precipitation process $[12,13]$. Therefore, the control of the sintering aid content is very important to analyze the sintering kinetics of Nd: YAG transparent ceramics.

In this paper, the densification process of Nd: YAG transparent ceramics with different contents of TEOS will be discussed in detail. The sintering kinetics of Nd: YAG transparent ceramics in a vacuum environment were investigated by the Johnson sintering model, and the sintering activation energy was calculated.

\section{Experimental}

High purity $\mathrm{Y}_{2} \mathrm{O}_{3}\left(\geq 99.999 \%\right.$, Alfa Aesar Company, USA), $\alpha-\mathrm{Al}_{2} \mathrm{O}_{3}(\geq 99.99 \%$, Alfa Aesar Company, USA), $\mathrm{Nd}_{2} \mathrm{O}_{3}(\geq 99.99 \%$, Alfa Aesar Company, USA) powders were weighted with chemical compositions of $\mathrm{Nd}_{0.03} \mathrm{Y}_{2.97} \mathrm{Al}_{5} \mathrm{O}_{12}$. The raw materials were poured into a high-purity $\mathrm{Al}_{2} \mathrm{O}_{3}$ ball mill tank with ethanol, and using 0, 0.5, 1.0, $3.0 \mathrm{wt} \%$ TEOS (Tetraethyl orthosilicate, $>99.99 \%$ ) as the sintering aid. In a solvent-free system, the probability of the reaction between TEOS and $\mathrm{H}_{2} \mathrm{O}$ is very low because the two liquid phases are separated. In the $\mathrm{C}_{2} \mathrm{H}_{5} \mathrm{OH}$ system, the probability of the reaction between TEOS and $\mathrm{C}_{2} \mathrm{H}_{5} \mathrm{OH}$ is very high because the miscibility and hydrolysis rate grows in two liquid phases. $\mathrm{Si}(\mathrm{HO})_{\times}\left(\mathrm{OC}_{2} \mathrm{H}_{5}\right)_{4-\mathrm{x}}$ is an unstable sol structure, which decomposes into $\mathrm{SiO}_{2}$ at high temperature $[14,15]$. The standard hydrolysis reaction is given as shown in Eq. (1):

$$
\mathrm{Si}\left(\mathrm{OC}_{2} \mathrm{H}_{5}\right)_{4}+\mathrm{xH}_{2} \mathrm{O} \rightarrow \mathrm{Si}(\mathrm{HO})_{\mathrm{x}}\left(\mathrm{OC}_{2} \mathrm{H}_{5}\right)_{4-\mathrm{x}}+\mathrm{xC}_{2} \mathrm{H}_{5} \mathrm{OH}
$$

All slurries were uniformly mixed with a high-purity $\mathrm{ZrO}_{2}$ grinding ball and air-dried at $60^{\circ} \mathrm{C}$ for $2 \mathrm{~h}$ followed by sieving through a 200 -mesh screen, after that, the mixture of the powders was calcined at $800^{\circ} \mathrm{C}$ for $4 \mathrm{~h}$ to eliminate organic residue. Green bodies with $19 \mathrm{~mm}$ in diameter and $2 \mathrm{~mm}$ in thickness were prepared from the powder mixtures under a uniaxial dry pressure of $10 \mathrm{MPa}$ and a cold isostatic pressure of $300 \mathrm{MPa}$. The obtained green bodies were named as $\mathrm{S}_{0}, \mathrm{~S}_{0.5}, \mathrm{~S}_{1.0}$, and $\mathrm{S}_{3.0}$, respectively. After sintering the green bodies at $1450^{\circ} \mathrm{C} \sim 1650^{\circ} \mathrm{C}$ for $1 \sim 2 \mathrm{~h}$ under vacuum $\left(1.0 \times 10^{-6} \mathrm{~Pa}\right)$, the obtained ceramics samples were annealed in air at $1450^{\circ} \mathrm{C}$ for $10 \mathrm{~h}$ and mirror polished on both surfaces.

The DTA curves of milled powder were measured by an SDT2960 thermal analyzer at a temperature ranging from $200^{\circ} \mathrm{C}$ to $1500^{\circ} \mathrm{C}$ with a heating rate of $10{ }^{\circ} \mathrm{C} / \mathrm{min}$. X-ray 
diffractometer (Rigaku $2500 \mathrm{PC}$, Japan) $\mathrm{Cu}-\mathrm{K} \alpha 1$ target radiation $(\lambda=1.054 \mathrm{~nm})$, the operating voltage is $40 \mathrm{kV}$, the current is $30 \mathrm{~mA}$, the test angle $(2 \theta)$ is $20 \sim 80^{\circ}$. The density of the Nd: YAG ceramics was investigated by the Archimedes drainage method. The SEM images and EDS spectra of samples were obtained by scanning electron microscope (SEM, JEOL, JSM-7610F) operated at $10 \mathrm{kV}$.

\section{Results and discussion}

\subsection{Densification mechanism for silica-doped Nd: YAG ceramic samples}

Fig.1 shows the grain arrangement process of ceramic samples from the initial stage to the final sintering stage. As the increase of temperature and the extension of time, the solid particles are interconnected, the crystal grains grow, and the pores and grain boundaries gradually decrease during the sintering process. When the contact area between particles increases, the total volume of the green bodies shrinks and the density increased. The number of pores of ceramic decreases ultimately in the final stage of sintering [16]. The common sintering assistant is TEOS, which decomposes into $\mathrm{SiO}_{2}$ at high temperatures. To further study the densification process of TEOS on the Nd: YAG, different contents of TEOS were added to discuss its densification and sintering kinetics in detail.

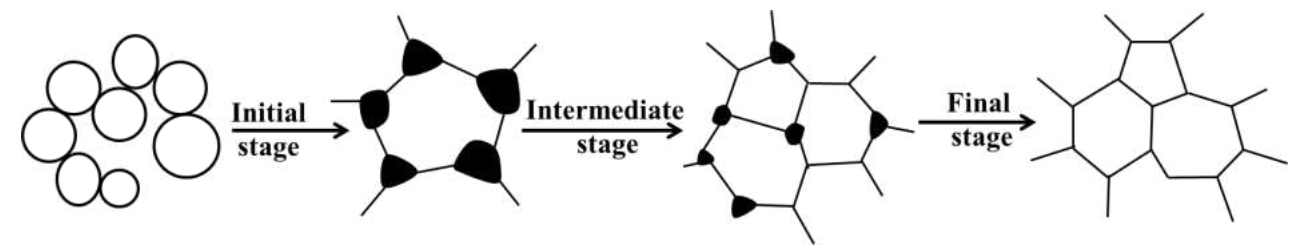

Fig. 1. The grain arrangement process of ceramic samples.

Fig. 2 shows the DTA analysis of Nd: YAG ceramic powder. As the temperature gradually increases, $\mathrm{Al}_{2} \mathrm{O}_{3}$ and $\mathrm{Y}_{2} \mathrm{O}_{3}$ gradually begin to react. An obvious exothermic peak at about $1350{ }^{\circ} \mathrm{C}$ was caused by the crystal form of the powder gradually changed from YAM to YAP, and then gradually changes from YAP to YAG [17]. Compared with the DTA curves without sintering aid, the exothermic peak intensity of the doped TEOS sample gradually reduced. Maybe the doping of TEOS affects the phase transition of the ceramic powders. The results will be further confirmed by the XRD pattern.

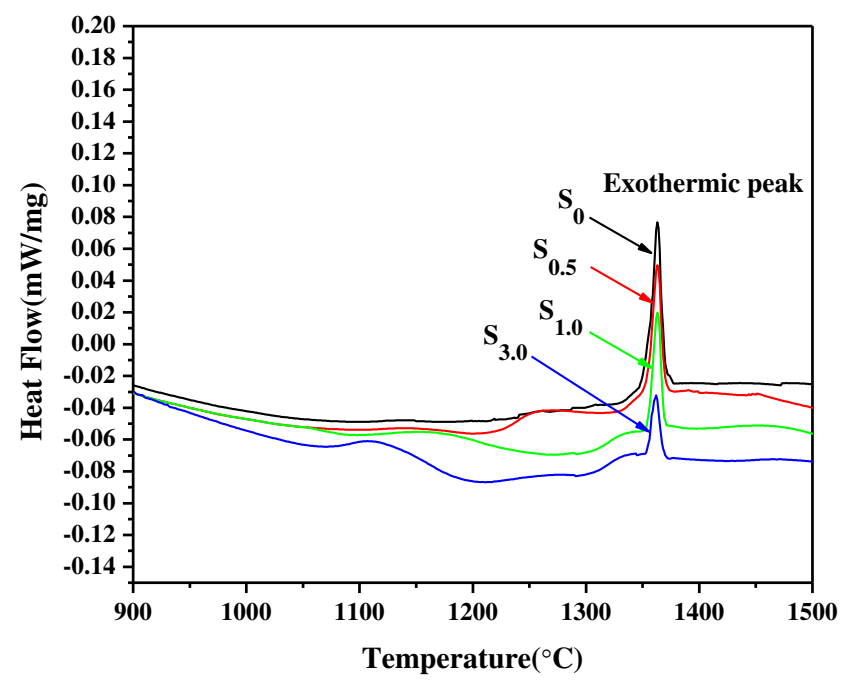

Fig. 2. DTA analysis of Nd: YAG ceramic powder. 
In order to verify the results of DTA analysis, ceramic samples sintered at $1650^{\circ} \mathrm{C}$ for $2 \mathrm{~h}$ were used for the XRD test, as shown in Fig. 3. All samples show a cubic crystal structure virtually identical to the YAG crystal phase (PDF\#33-0040, space group Ia3d). When the content of the TEOS was $3.0 \mathrm{wt} \%$, a small amount of YAP crystal phase appears in the diffraction peak. After TEOS thermal decomposition, $\mathrm{SiO}_{2}$ was reacted with a small number of $\mathrm{Y}_{2} \mathrm{O}_{3}$ to form the $\mathrm{Y}_{2} \mathrm{Si}_{2} \mathrm{O}_{7}$ crystal phase. Hence, the lattice structure of YAG tends to be incomplete and the crystal phase of YAP appeared.

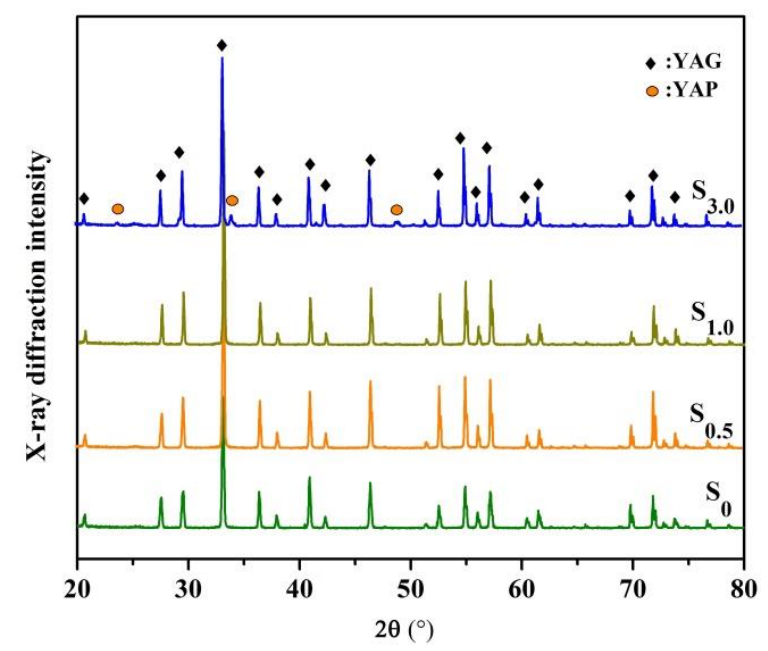

Fig. 3. XRD pattern of Nd: YAG ceramic sample sintered at $1650^{\circ} \mathrm{C}$ for $\mathbf{2} \mathrm{h}$.

Fig. 4 shows the SEM images of $\mathrm{Nd}$ : YAG ceramic samples sintered at $1500-1600^{\circ} \mathrm{C}$ for $2 \mathrm{~h}$. When the ceramic samples were sintered at $1500^{\circ} \mathrm{C}$ for $2 \mathrm{~h}$, the pores on the ceramic surface gradually decrease, the crystal grains grow gradually, and the density of the ceramic sample further increases with the increase of the sintering aid content. The average particle size of the $\mathrm{S}_{3.0}$ sample sintered at $1500^{\circ} \mathrm{C}$ reached $1.2 \mu \mathrm{m}$. The result indicated that the increase of TEOS content facilitates the densification process of Nd: YAG ceramic at the same sintering temperature. However, the abnormal grain growth results from excess TEOS. Although the densification process of transparent ceramics was accelerated, there will be the formation of secondary phases. This SEM result is consistent with the XRD pattern.

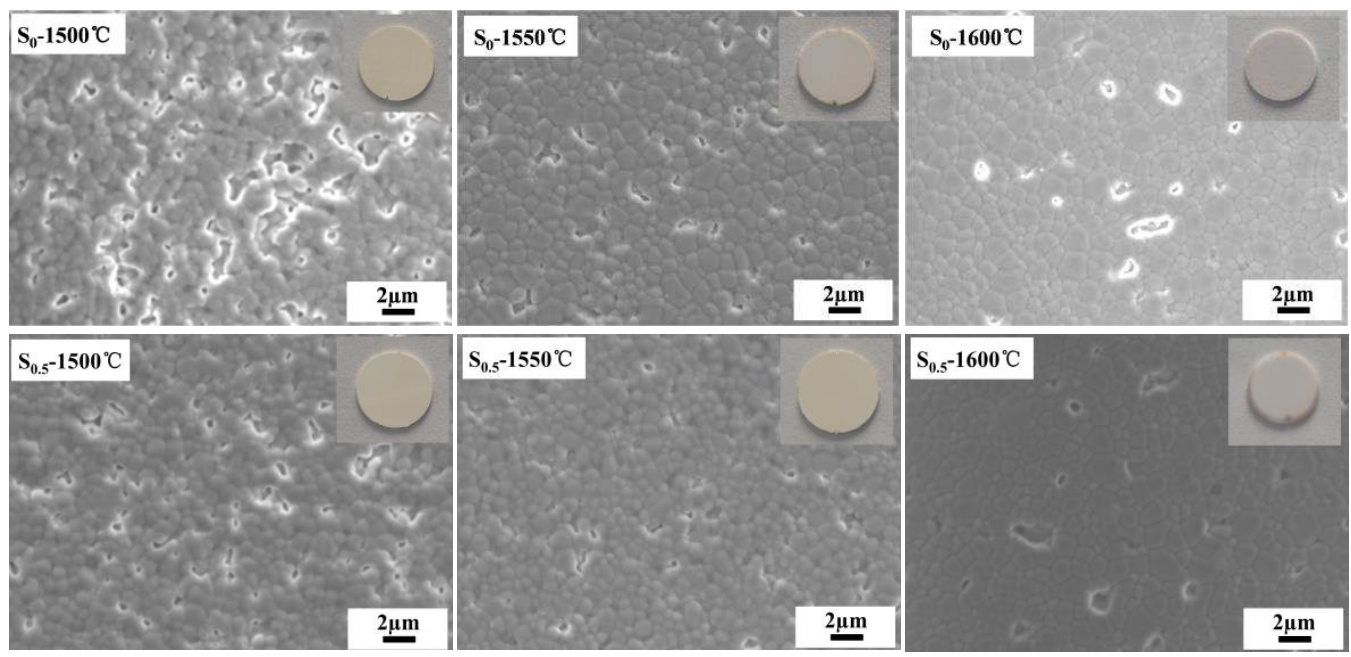




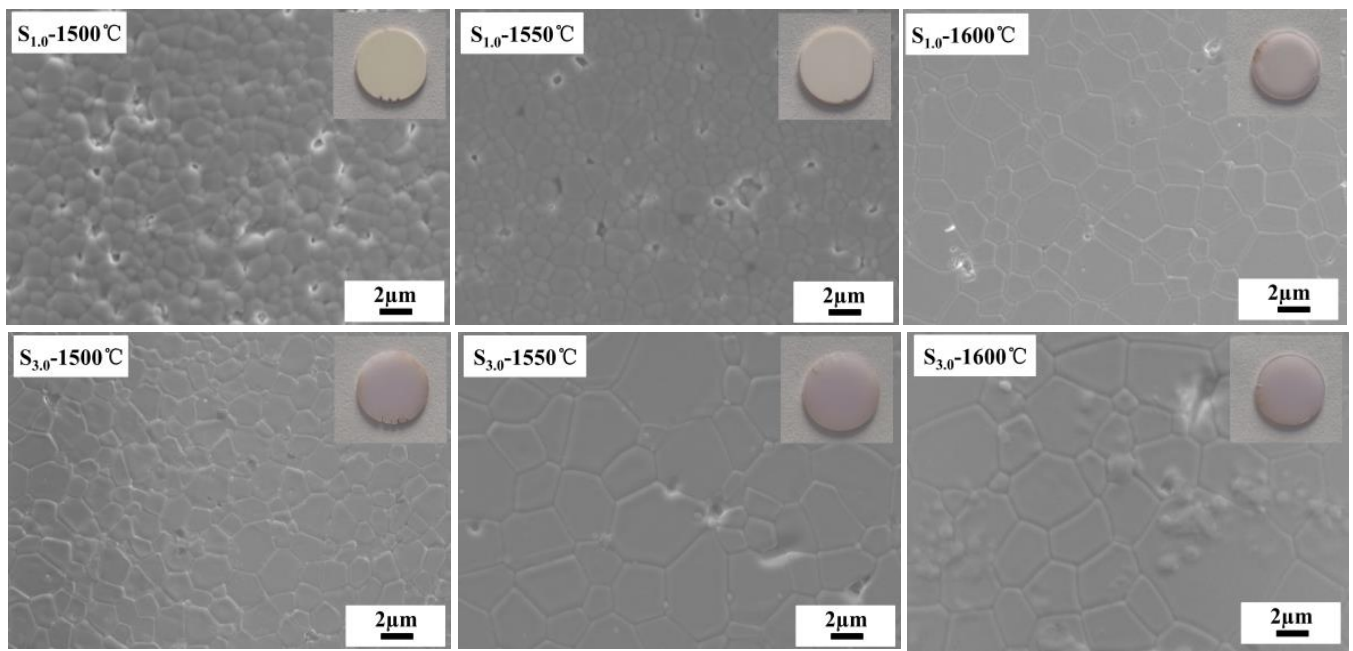

Fig. 4. SEM images of Nd: YAG ceramic samples sintered at 1500-1600 ${ }^{\circ} \mathrm{C}$ for $2 \mathrm{~h}$

Combined with the SEM images of the ceramic samples, the influence of sintering temperature on the average grain size and relative density were investigated, as shown in Fig. 5. As the TEOS content increased from 0.5 to $3.0 \mathrm{wt} \%$, the average grain size and relative density of ceramic samples increased. Besides, the grain size and relative density increased as the sintering temperature increased. When the sintering temperature is higher than $1600^{\circ} \mathrm{C}$, the growth rate of crystal grains rapidly increased. Therefore, the results indicated the doping of TEOS accelerated the growth of ceramic grains.

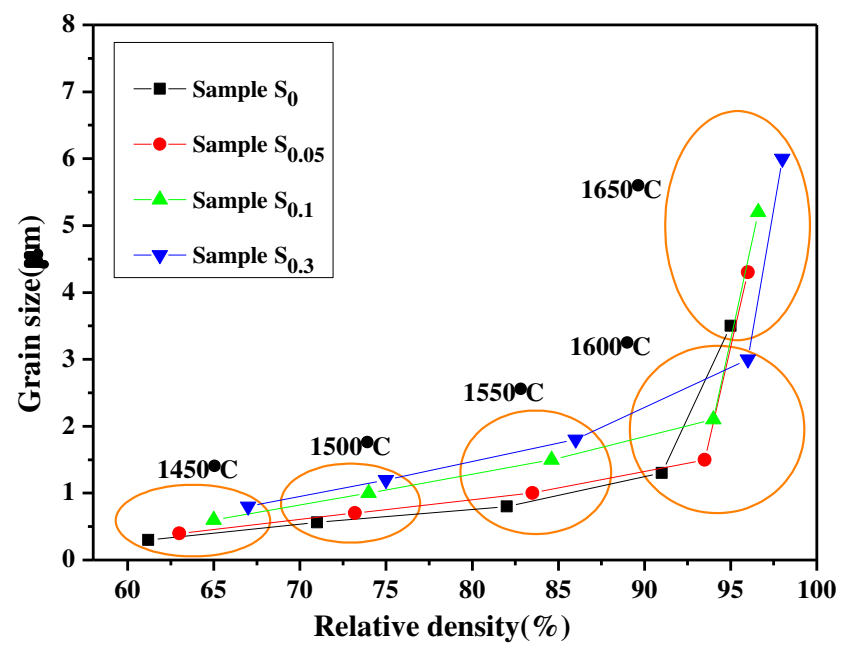

Fig. 5. Influence of sintering temperature on the average grain size and relative density.

\subsection{Sintering kinetics of Nd: YAG ceramic samples.}

\subsubsection{Johnson sintering model analysis}

In general, the kinetics of densification for ceramics was investigated by the thermal expansion curve. However, the measurement curve cannot truly reflect the change of the shrinkage rate of the green bodies measured in a vacuum sintering environment. To accurately measure the shrinkage rate of the sample with sintering temperature and time, the prepared green bodies were raised to $1450-1650^{\circ} \mathrm{C}$ at a heating rate of $20^{\circ} \mathrm{C} / \mathrm{min}$ under a vacuum environment $\left(\mathrm{P}_{\mathrm{T}} \leq 10^{-6} \mathrm{~Pa}\right)$ for $0-2 \mathrm{~h}$, and then cooled with the furnace. Accurately measure the size of the Nd: YAG ceramic samples with a vernier caliper.

In this paper, the calculation method of the Johnson sintering model $[18,19]$ is adopted. 
Assuming that grain growth is negligible during the initial stage, the shrinkage equations are a reasonable assumption. To determine the dominant diffusion mechanism controlling the densification, the relationship between sample shrinkage and temperature can be expressed by the following formulas (2) and (3):

$$
\begin{aligned}
& \text { Grain boundary diffusion: } \quad \frac{\Delta L}{L_{0} T} \\
& =\left(\frac{2.14 \gamma \Omega D_{0 B} R}{c k r^{4} Q T^{2}}\right)^{1 / 3} \exp \left(-\frac{Q}{3 R T}\right) \\
& \\
& \quad \text { Volume diffusion: } \frac{\Delta L}{L_{0} T} \\
& =\left(\frac{5.34 \gamma \Omega D_{0 v} R}{c k r^{3} Q T^{2}}\right)^{1 / 2} \exp \left(-\frac{Q}{2 R T}\right)
\end{aligned}
$$

Where $\Delta L=L_{0}-L$ is the change in sample length during the sintering process, $L_{0}$ is the initial length of the sample, $T$ is the absolute temperature, $\gamma$ is the surface energy, $k$ is the Boltzmann constant, $r$ is the particle size, $\Omega$ is the void volume, $R$ is the gas constant, $c$ is the heating rate, $Q$ is the sintering activation energy, $D_{0 B}$ is the grain boundary diffusion coefficient, and $D_{0 V}$ is the volume diffusion coefficient.

The influence of temperature on $\exp (-n Q / R T)$ in Eq. (2)-(3) is far greater than other factors in the equations. If the entire sintering process does not consider the specific diffusion matrix, the slope $(-n Q / R)$ of the relationship between $\ln \left[\left(\Delta L / L_{0} T\right)\right]$ and $1 / T$ can be used to calculate the apparent activation energy $n Q$. Among them, $n=1 / 3$ is grain boundary diffusion, and $n=1 / 2$ is volume diffusion. Therefore, this paper uses the Johnson model to study sintering activation energy.

Furthermore, the relationship between the green body sintering shrinkage $\Delta L / L_{0}$ and the sintering time $t$ can be expressed as formulas (4):

$$
=\left(\frac{K \gamma V D}{k r^{P} T}\right) \mathrm{m}_{t^{m}}
$$

Taking the logarithm of both sides of formula (4) shows that $\ln \left(\Delta L / L_{0}\right)$ has a linear relationship with $l n t$, and the value of $\mathrm{m}$ can be determined from the slope of the curve to determine the mass transfer mechanism of sintering. In general, when the $m$ is close to 3.01, the grain boundary diffusion is mainly the sintering mechanism. When the $m$ is close to 0.4 , the volume diffusion is mainly the sintering mechanism.

\subsubsection{Calculation of sintering activation energy of Nd: YAG ceramics samples.}

The linear shrinkage rate $\ln \left(\Delta L / L_{0}\right)$ showed a good linear relationship with the sintering time lnt at logarithmic coordinates, as shown in Fig. 6 . The curve of the green bodies doped with $0 \sim 3.0 \mathrm{wt} \%$ TEOS is linearly fitted, and the linear slopes are 3.02064, 0.21211, 0.2461, and 0.2580 , respectively, and these values are close to 3.01 . Therefore, the results indicated that the mass transfer of ceramic samples doped with different concentrations of TEOS is mainly carried out through the grain boundary diffusion.

Fig. 7 shows the $\ln \left(\Delta L / L_{0} T\right)$ and $1 / T$ sintering kinetic curves of the Nd: YAG ceramic sample under the vacuum ambient. The results of $\ln \left(\Delta L / L_{0}\right) \sim \ln t$, which indicated that the mass transfer of ceramic samples under vacuum ambient is mainly carried out through grain 
boundary diffusion, so $n=1 / 3$. Combine the relationship between shrinkage rate and temperature in formula (2), the sintering activation energy $Q$ of different Nd: YAG transparent ceramic samples are calculated. The sintering activation energy of the ceramic samples is $549.75,416.03,354.19$, and $322.68 \mathrm{~kJ} \cdot \mathrm{mol}^{-1}$.
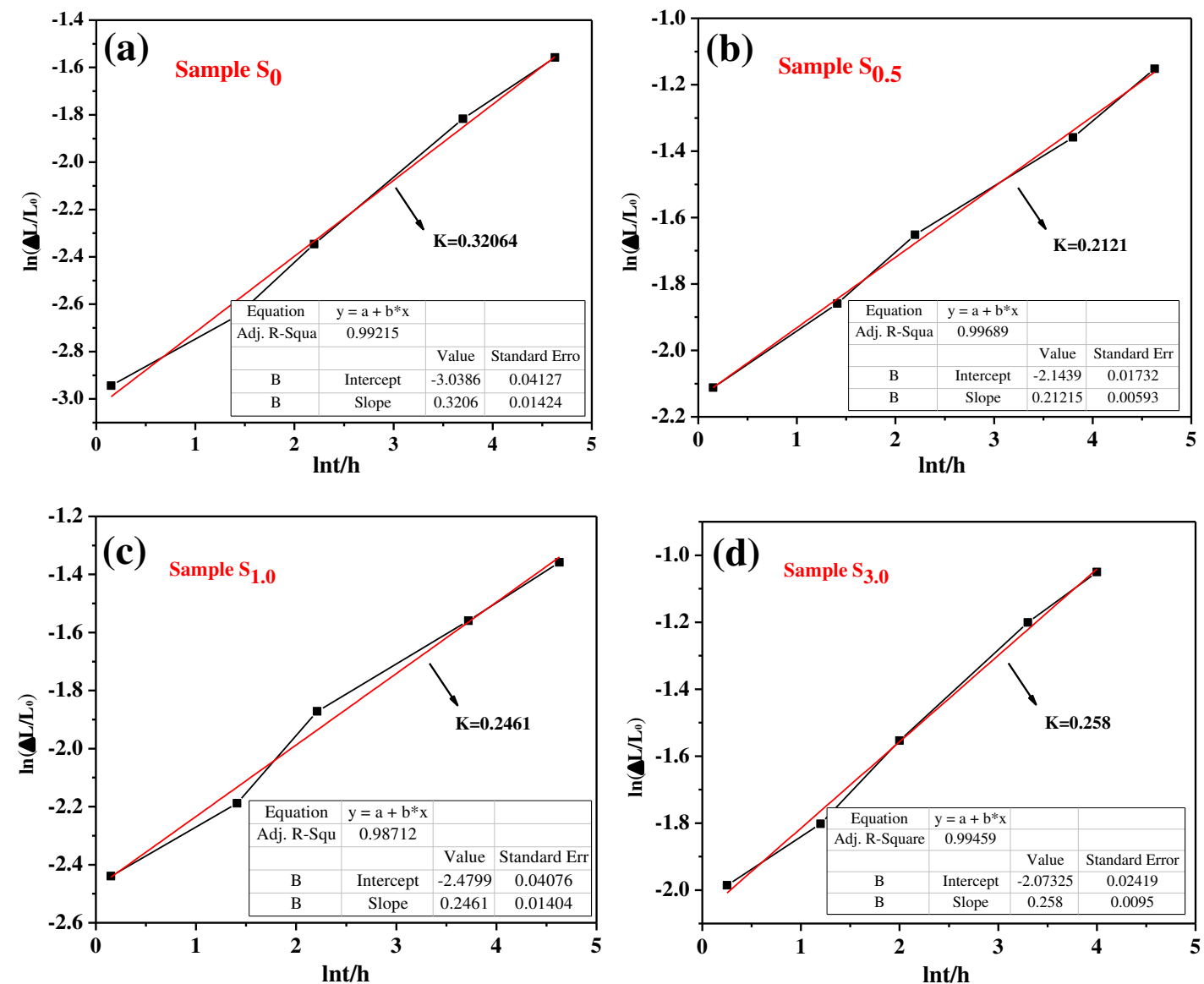

Fig. 6. The relationship curve between $\ln \left(\Delta L / L_{0}\right)$ and $\ln t$ of different ceramic samples.

The sintering mechanism of samples without TEOS is mainly grain boundary diffusion. The addition of TEOS is beneficial to promote the sintering of Nd: YAG transparent ceramics. TEOS is thermally decomposed into $\mathrm{SiO}_{2}$, and part of $\mathrm{Si}^{4+}$ replaces the $\mathrm{Al}^{3+}$ in the $\mathrm{Nd}$ : YAG lattice increases the cation vacancy concentration, and the diffusion coefficient of the substance in the solid-phase sintering process is proportional to the related defect concentration [20]. Therefore, the diffusion of $\mathrm{Nd}^{3+}, \mathrm{Y}^{3+}$, and $\mathrm{Al}^{3+}$ ions is accelerated, thereby promoting the densification process of Nd: YAG transparent ceramics. The sintering activation energy of the whole system has been greatly reduced after the addition of TEOS. Among them, the sintering activation energy of the sintering system with $0.5 \mathrm{wt} \%$ TEOS decreased the most. The decrease of sintering activation energy fully shows that the addition of TEOS promoted the sintering of the Nd: YAG transparent ceramics. 

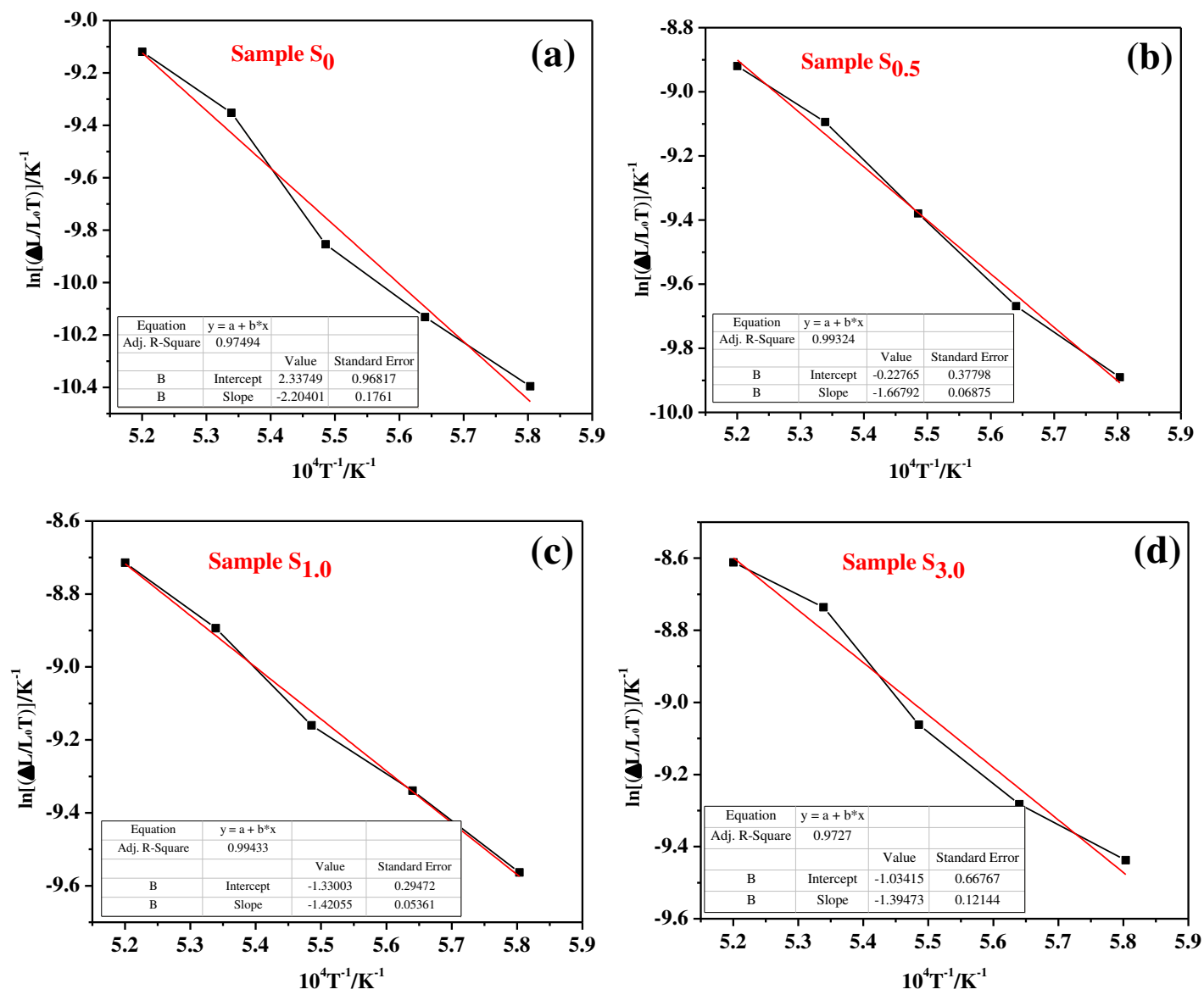

Fig. 7. The $\ln \left(\Delta L / L_{0} T\right) \sim 1 / T$ sintering kinetic curve of Nd: YAG ceramic samples.

The analysis of the vacuum sintering process was summarized as: In the initial stage of sintering, surface diffusion dominates, and the partial formation of necks between particles is accompanied by the appearance of grain boundaries. With the rapid increase of temperature, the sintering activation energy of the material is significantly reduced, and surface diffusion is replaced by volume diffusion and grain boundary diffusion. In the later stage of sintering, the densification process is gradually controlled by the grain boundary diffusion. The particles realize material transport under the action of the grain boundary diffusion, and the pores are rapidly transported along the grain boundary to the surface to achieve densification. Due to the fast heating rate, the grain boundary is in a non-equilibrium state with high grain boundary energy, the material migration rate is fast, and the crystal grains and pores are easily transported and discharged along the grain boundary in a vacuum state, which promotes diffusion and achieves rapid densification.

\section{Conclusion}

In this work, the densification process and sintering kinetics of Nd: YAG ceramic samples doped with $0 \sim 3.0 \mathrm{wt} \%$ TEOS was investigated by the vacuum sintering method. When the amount of TEOS increased from $0 \mathrm{wt} \%$ to $3 \mathrm{wt} \%$, the densification rate of ceramic samples increased significantly. A small amount of YAP crystal phase of the $S_{3.0}$ sample was found by XRD pattern. At the same time, the sintering kinetics of ceramic products is analyzed by the Johnson model. The sintering activation energy of the ceramic samples decreased from $549.75 \mathrm{~kJ} \cdot \mathrm{mol}^{-1}$ to $322.68 \mathrm{~kJ} \cdot \mathrm{mol}^{-1}$ as the increase of the sintering aid content. 
The addition of TEOS is beneficial to reduce the sintering activation energy. To avoid the appearance of the second phase and impurities, the doping amount of TEOS should be strictly controlled between 0.5 and $1.0 \mathrm{wt} \%$.

\section{Acknowledgments}

This work was supported by the Project of the Jilin Province Development and Reform Commission (2019C028) and the Project of Jilin Provincial Science and Technology Department (20190302041GX).

\section{Reference}

[1] C. Jia, L. Li, Y. Liu, B. Fang, H. Ding, J.N. Song, Y.B. Liu, K.J. Xiang, S. Lin, Z.W. Li, W.J. Si, B. Li, X. Sheng, D.Z. Wang, X.D. Wei, H. Wu, Highly compressible and anisotropic lamellar ceramic sponges with superior thermal insulation and acoustic absorption performances. Nat. Commun. 11(1), 1-13 (2020).

[2] G. Żyła, M. Cholewa, A. Witek, Dependence of viscosity of suspensions of ceramic nanopowders in ethyl alcohol on concentration and temperature. Nanoscale. Res. Lett. 7(1), 1-10 (2012).

[3] S.H. Lee, S. Kochawattana, G.L. Messing, J.Q. Dumm, V. Castillo, Solid-state reactive sintering of transparent polycrystalline Nd: YAG ceramics. J. Am. Ceram. Soc. 89(6), 19451950 (2006).

[4] A. Ikesue, I. Furusato, K. Kamata, Fabrication of polycrystalline, transparent YAG ceramics by a solid-state reaction method. J. Mater. Res. 78, 225-228 (1995).

[5] A. Ikesue, L.A. Yan, T. Yoda, S. Nakayama, T. Kamimura, Fabrication and laser performance of polycrystal and single crystal Nd: YAG by advanced ceramic processing. Opt. Mater. 29(10), 1289-1294 (2007).

[6] D.X. Yan, H. Pang, B. Li, R.Vajtai, L. Xu, P.G. Ren, J.H. Wang, Z.M. Li, Structured reduced graphene oxide/polymer composites for ultra-efficient electromagnetic interference shielding. Adv. Funct. Mater. 25(4), 559-566 (2015).

[7] H. Shahbazi, M. Tataei, M.H. Enayati, A. Shafeiey, M. Azizi. Malekabadi, Structuretransmittance relationship in transparent ceramics. J. Alloys. Compd. 785, 260-285 (2019).

[8] L. Ge, J. Li, Z.W. Zhou, B.L. Liu, T.F. Xie, J. Liu, H.M. Kou, Y. Shi, Y.B. Pan, J.K. Guo, Nd: YAG transparent ceramics fabricated by direct cold isostatic pressing and vacuum sintering. Opt. Mater. 50, 25-31 (2015).

[9] Q.B. Li, M. Wang, Y.P. Liang, L.Y. Lin, T. Fu, P.T. Wei, T.F. Peng, Molecular dynamics simulations of aggregation of copper nanoparticles with different heating rates. Physica. E. 90, 137-142 (2017).

[10] S. Jiang, Y. Zhang, Y. Gan, Z, Chen, H. Peng, Molecular dynamics study of neck growth in laser sintering of hollow silver nanoparticles with different heating rates. J. Phys. D: Appl. Phys. 46(33), 1-11 (2013).

[11] Y.H. Huang, D.L. Jiang, J.X. Zang, Z.M. Chen, Q.L. Lin, Z.R. Huang, Sintering kinetics of YAG ceramics. J. Rare. Earth. 35, 416-422 (2014).

[12] V.I. Nizhenko, V.Y. Petrishchev, V.V. Skorokhod, Effect of liquid phase on the densification of tungsten-copper and molybdenum-copper pseudo alloys in sintering. Powder. Metall. Met. C+. 47(3-4), 163-170 (2008). 
[13] Y.F. Chai, W.T. Yu, J.L. Zhang, S.L. An, J. Peng, Y.Z. Wang, Influencing mechanism of $\mathrm{Al}_{2} \mathrm{O}_{3}$ on sintered liquid phase of iron ore fines based on thermal and kinetic analysis. Ironmak. Steelmak. 46(5), 424-430 (2019).

[14] J. Gnado, P. Dhamelincourt, C. Pelegris, M, Traisnel, Raman spectra of oligomeric species obtained by tetraethoxysilane hydrolysis-polycondensation process. J. Non-Cryst. Solids. 208(3), 247-258 (1996).

[15] I.G. Marino, P.P. Lottici, D. Bersani, R. Raschella, A. Lorenzi, A. Montenero, Micro-Raman monitoring of solvent-free TEOS hydrolysis. J. Non-Cryst. Solids. 351, 495-498 (2005).

[16] G. Okuma, D.K. Kadowaki, T. Hondo, S. Tanaka, F. Wakai, Interface topology for distinguishing stages of sintering. Sci. Rep. 7(11106), 1-9 (2017).

[17] A.J. Stevenson, E.R. Kupp, G.L. Messing, Low temperature, transient liquid phase sintering of $\mathrm{B}_{2} \mathrm{O}_{3}-\mathrm{SiO}_{2}$-doped Nd: YAG transparent ceramics. J. Mater. Res. 26(9), 1151-1158 (2011).

[18] D.L. Johnson, New Method of Obtaining Volume, Grain Boundary, and Surface Diffusion Coefficients from Sintering Data. J. Appl. Phys. 40, 192-200 (1969).

[19] X. Zhang, S. Liang, Study on the sintering kinetics of transparent alumina ceramic. J. Synth Cryst. 47(12), 2555-2560 (2018).

[20] M. Kuklja, Defects in yttrium aluminum perovskite and garnet crystals: atomistic study. J. Phys. Condens. Matter. 12(13), 2953-2967 (2000). 


\section{Declaration of Interest Statement}

The authors declare that they have no known competing financial interests or personal relationships that could have appeared to influence the work reported in this paper. 
Figures

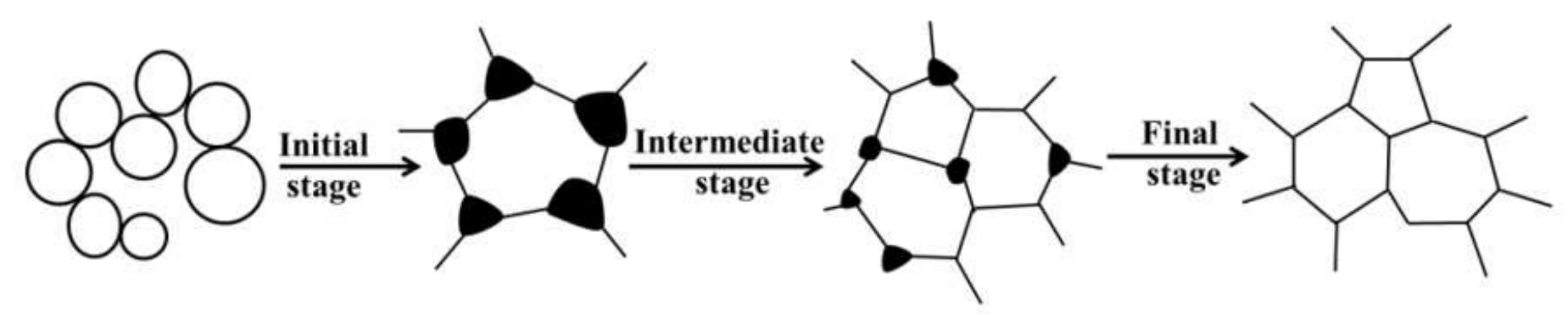

Figure 1

The grain arrangement process of ceramic samples.

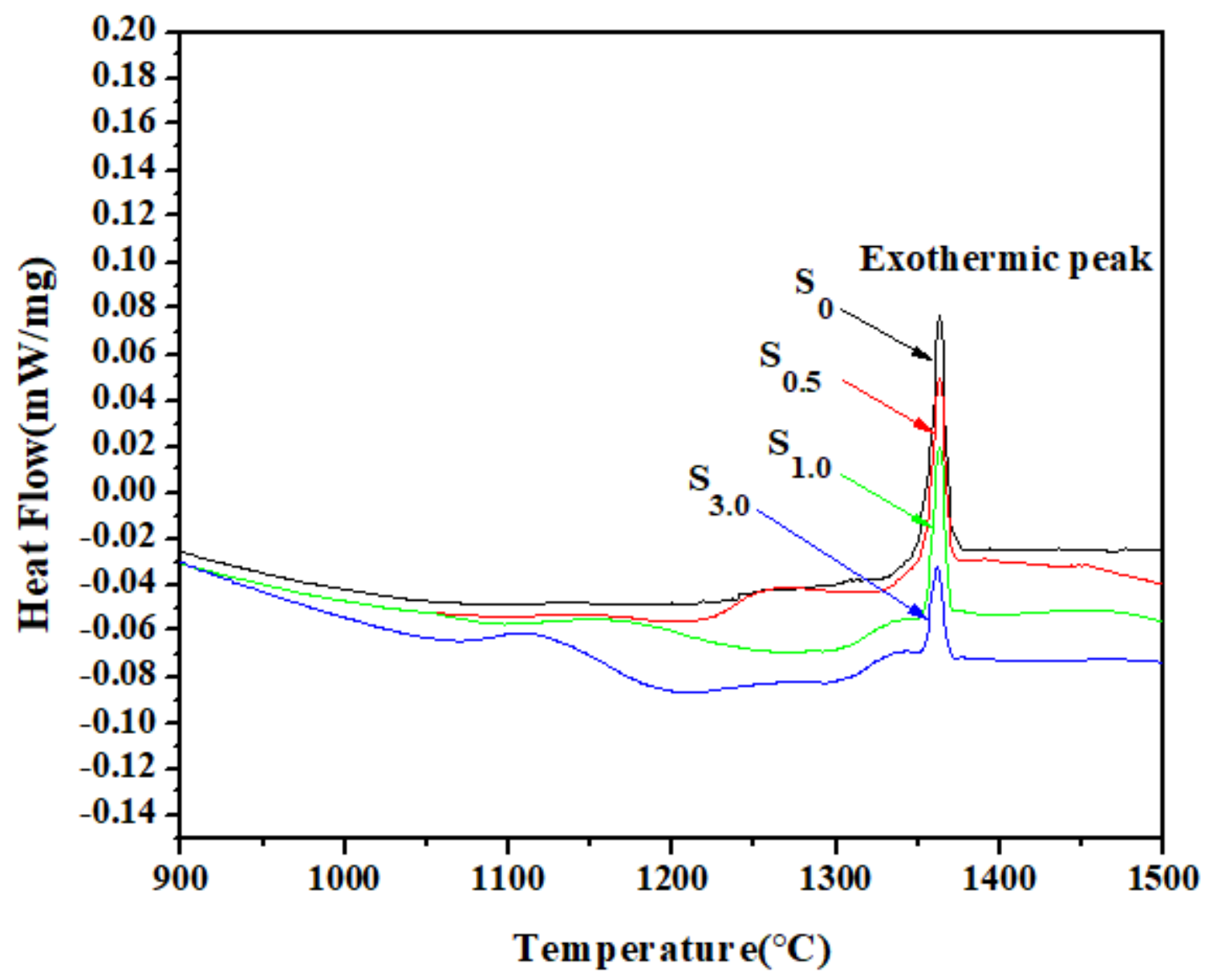

Figure 2

DTA analysis of Nd: YAG ceramic powder. 


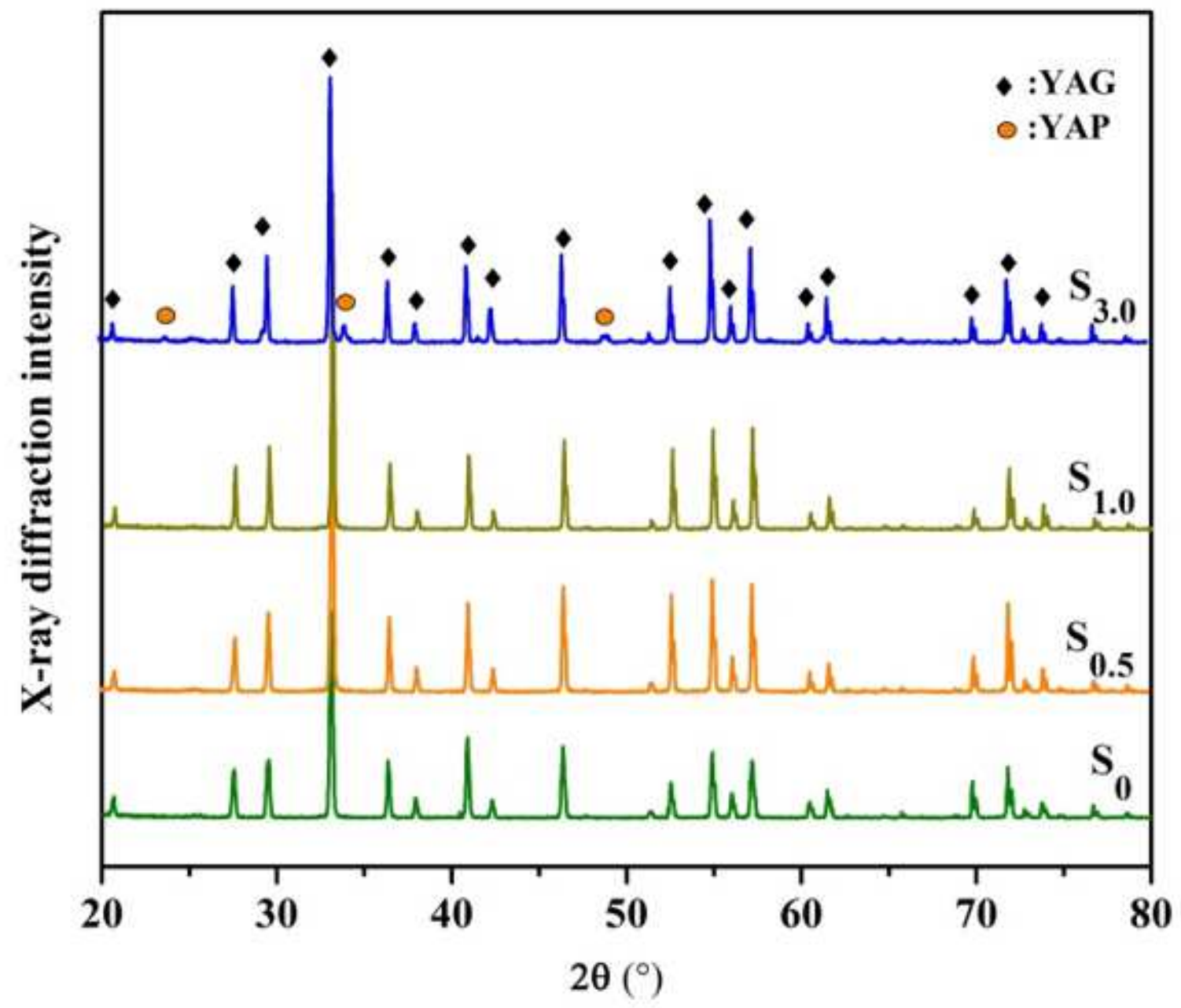

Figure 3

XRD pattern of Nd: YAG ceramic sample sintered at $1650^{\circ} \mathrm{C}$ for $2 \mathrm{~h}$. 

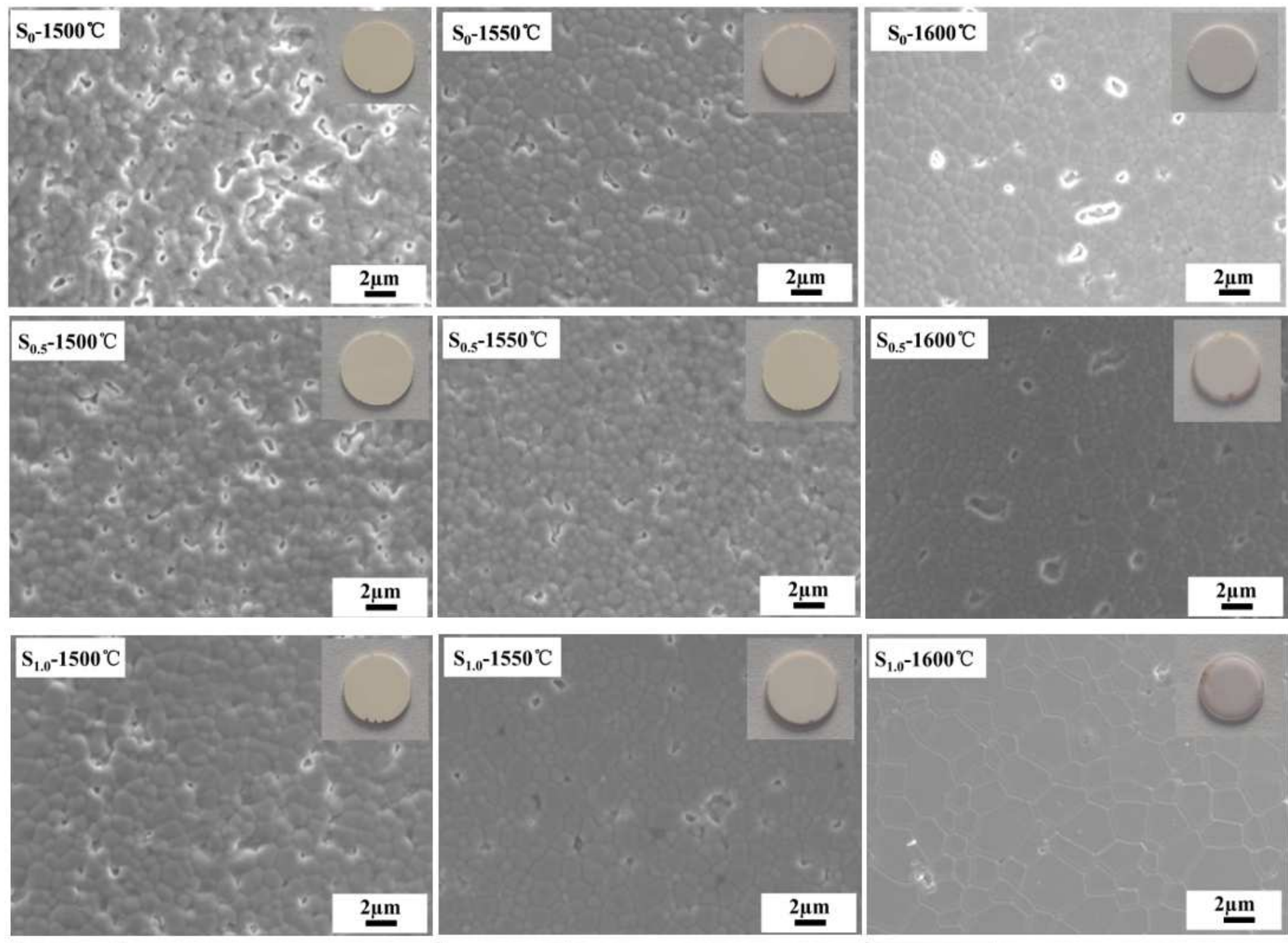

\section{$S_{1.0}-1600{ }^{\circ} \mathrm{C}$}
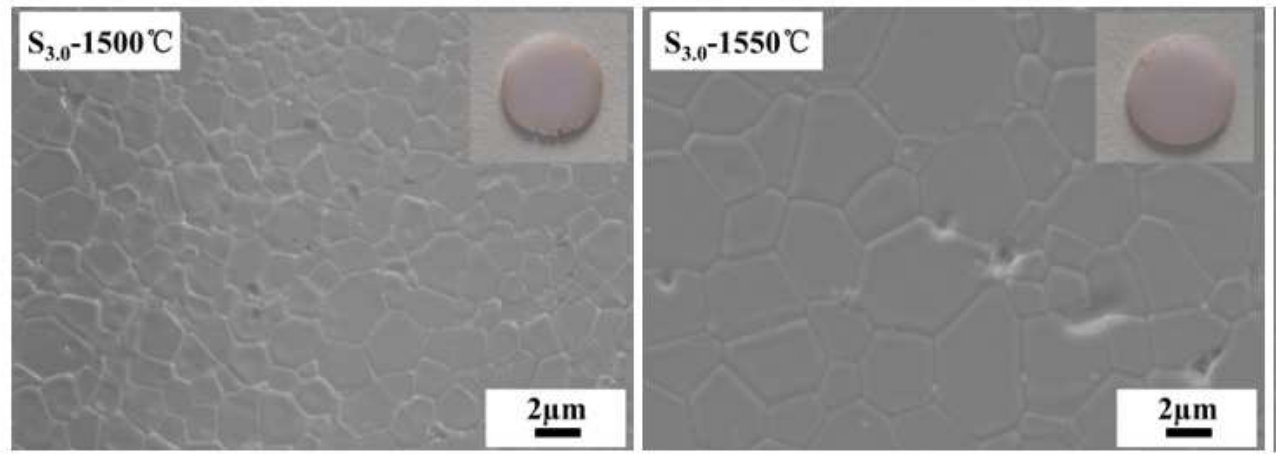

$S_{3.0^{-1600}} \mathrm{C}$

$2 \underline{\underline{\mu m}}$

\section{Figure 4}

SEM images of Nd: YAG ceramic samples sintered at $1500-1600^{\circ} \mathrm{C}$ for $2 \mathrm{~h}$ 


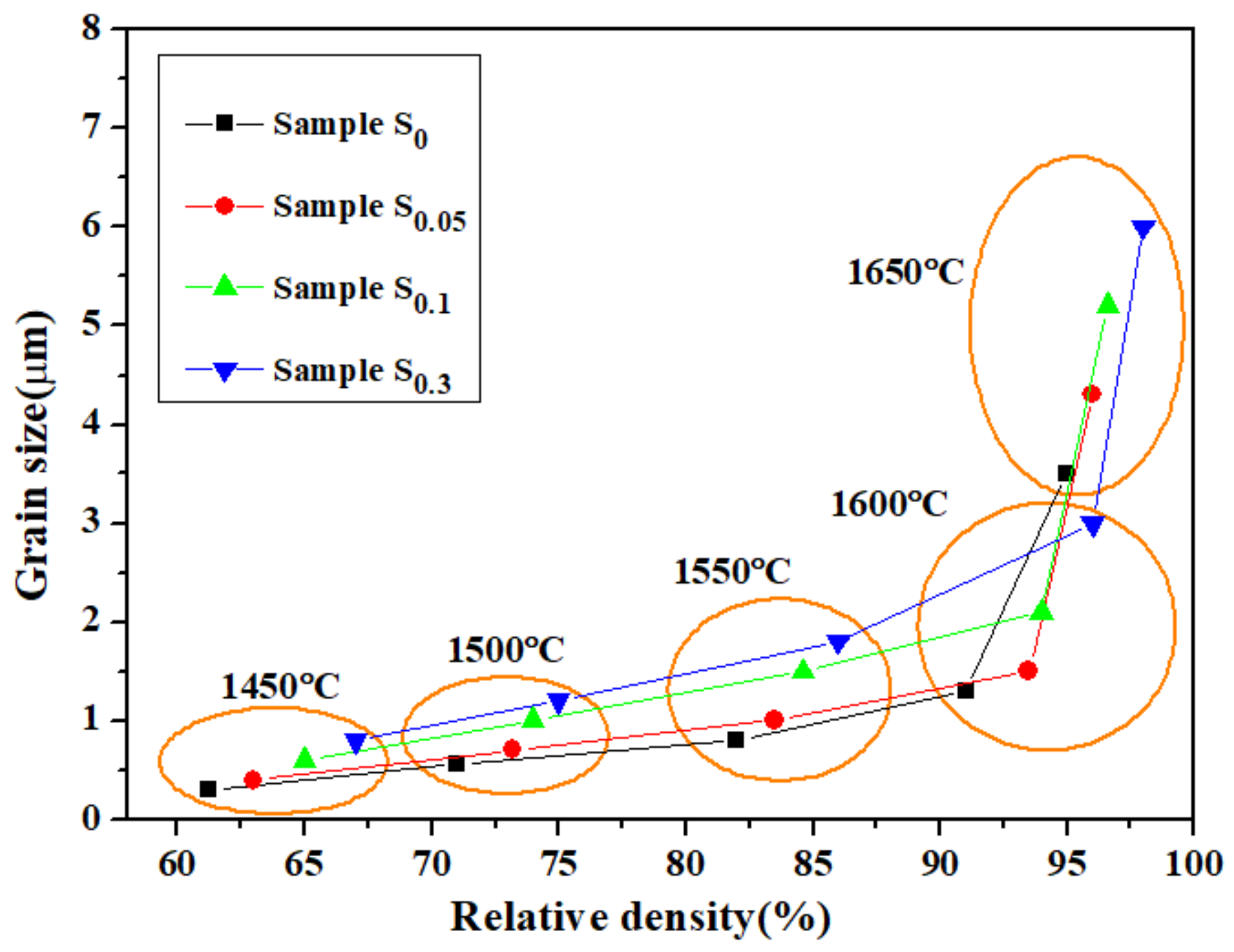

Figure 5

Influence of sintering temperature on the average grain size and relative density. 

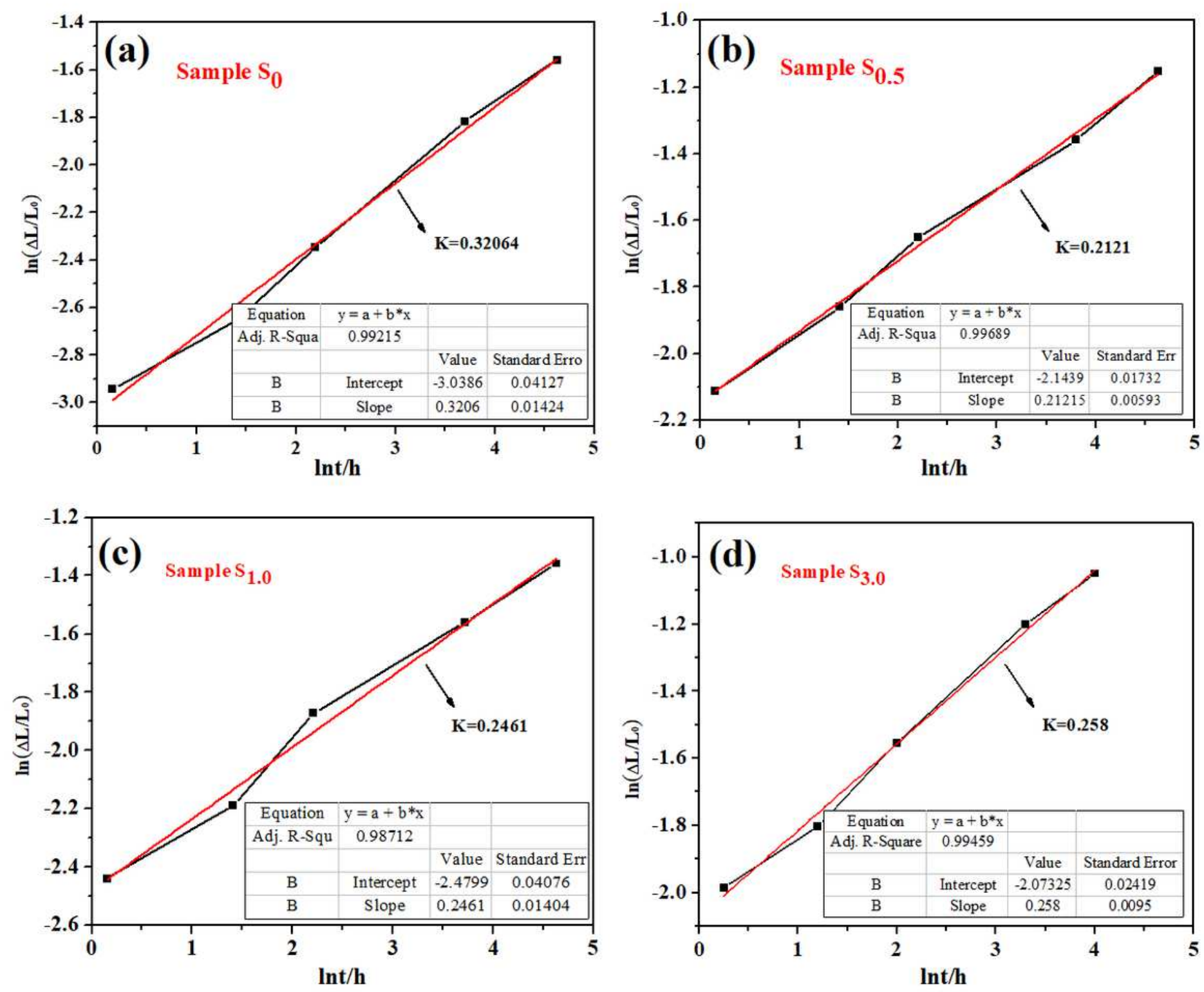

Figure 6

The relationship curve between $\ln (\Delta \mathrm{L} / \mathrm{L} 0)$ and Int of different ceramic samples. 

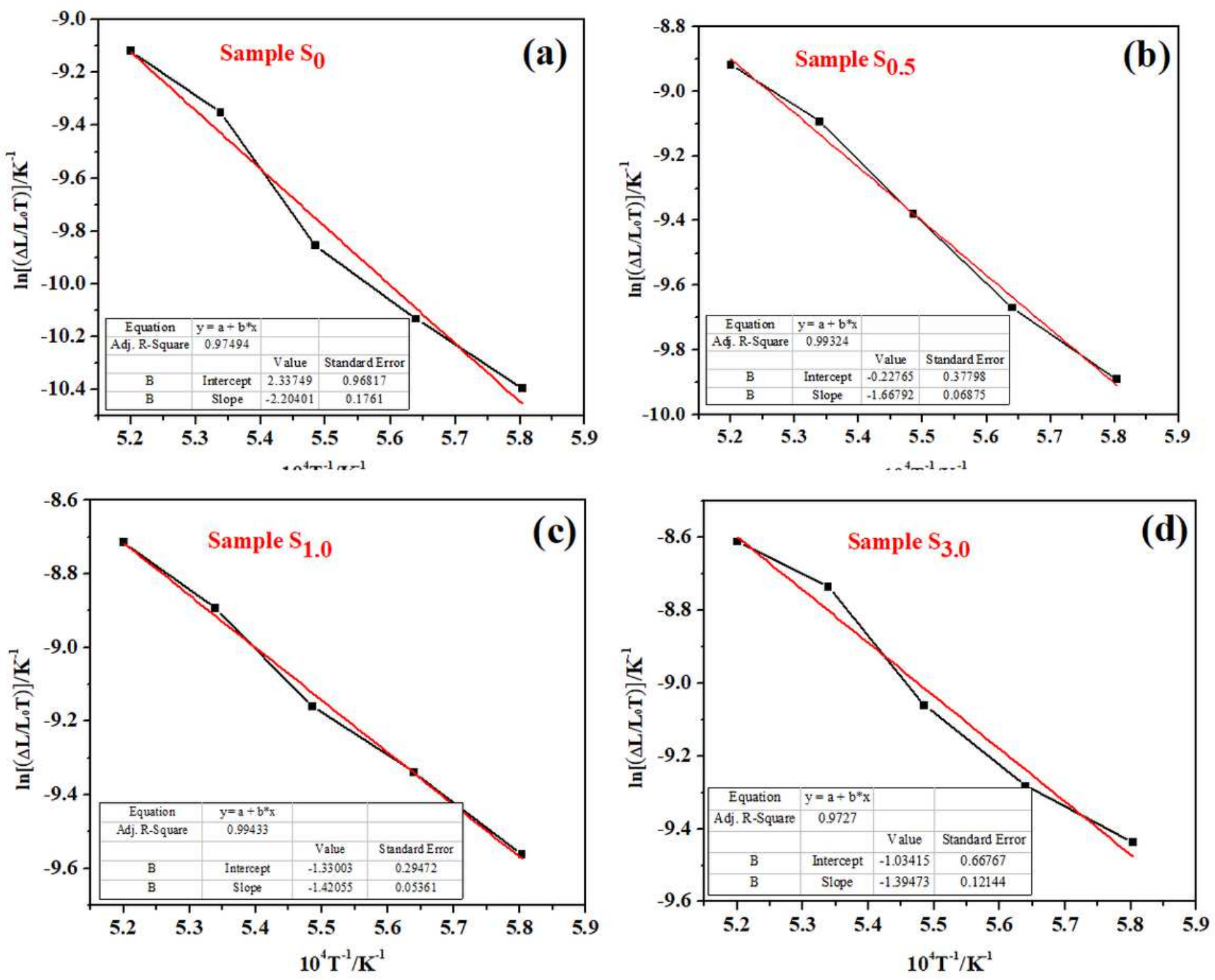

Figure 7

The $\ln (\Delta \mathrm{L} / \mathrm{L} 0 \mathrm{~T}) \otimes 1 / \mathrm{T}$ sintering kinetic curve of Nd: YAG ceramic samples. 